\title{
Persistent hiccups following cervical epidural steroid injection with betamethasone
}

This article was published in the following Dove Press journal: International Medical Case Reports Journal

\section{Matthew L Ritz \\ Christopher Bailey \\ Katherine Overstreet Andrew Gorlin}

Department of Anesthesiology, Mayo Clinic Hospital, Phoenix, AZ, USA
Correspondence: Matthew L Ritz; Andrew Gorlin Department of Anesthesiology, Mayo Clinic Hospital, 5777 E Mayo Blvd, Phoenix, AZ 85054, USA

Tel + I 4805156296 Email ritz.matthew@mayo.edu; gorlin.andrew@mayo.edu

\begin{abstract}
Singultus (hiccups lasting longer than 48 hours) is a described complication following epidural steroid injections, sacroiliac joint injections, and facet joint injections. The underlying etiology is not completely understood, but it is a condition that can be distressing to patients. Our case presentation involves a 62-year-old male presenting for cervical epidural steroid injection. He subsequently developed persistent hiccups that resolved after medical therapy. When approaching these patients, it is critical to evaluate for potentially life-threatening etiologies before progressing down a treatment algorithm.
\end{abstract}

Keywords: singultus, epidural steroid injection, persistent hiccups, betamethasone

\section{Case presentation}

The patient was a 62-year-old male with a past medical history significant for coronary artery disease, hypertension, as well as bilateral neck and shoulder pain. Magnetic resonance imaging of his cervical spine showed bilateral mild-to-moderate for aminal stenosis at $\mathrm{C} 5-\mathrm{C} 6$ and mild right for aminal stenosis at $\mathrm{C} 6-\mathrm{C} 7$. He underwent an uneventful C7-T1 epidural steroid injection under fluoroscopic guidance. Twelve milligram of betamethasone mixed with $2 \mathrm{~mL}$ of preservative free normal saline was injected into the epidural space without complication. The next day, the patient called the pain clinic after developing hiccups that had started in the morning and persisted into the afternoon. The patient had tried traditional, nonpharmacologic therapies (including breath holding and sips of water) without symptom resolution. After telephone interview and ruling out serious pathology, the patient was prescribed thorazine $10 \mathrm{mg}$ q6 hours PRN and his hiccups had resolved by the following day. As the patient has been lost to follow-up, patient consent for publication of this case was not possible. The details have been sufficiently anonymized not to cause harm to the patient.

\section{Discussion}

Hiccups are spontaneous, myoclonic contractions of the diaphragm and, in many cases, the intercostal musculature. ${ }^{2}$ The involved structures in the hiccup reflex arc can be divided into the afferent limb, the reflex center, and the effector limb. The afferent limb is composed of the vagal nerve as well of portions of the thoracic sympathetic chain located T6-T12. The reflex center is believed to be located in the hypothalamus, the brainstem, and the cervical spinal cord, C3-C5. The effector limb is composed primarily of the phrenic nerve. ${ }^{3}$ The vagal nerve also branches to the recurrent laryngeal nerve, stimulation of which leads to forced closure of the glottis. ${ }^{2}$ 
Any process that affects the afferent limb, reflex center, or efferent limb can lead to the development of hiccups; thus, the differential diagnosis is extensive and includes multiple organ systems. Most commonly, pathology in the gastrointestinal tract is implicated; peptic ulcer disease, gastritis, malignancy, and hemorrhage are several examples. Diseases of the central nervous system, cardiovascular system, and toxic metabolic syndromes such as uremia are all on the differential as well.

The exact pathophysiology of the development of hiccups following image-guided injections is not completely understood. Initially, potentially life-threatening causes must be excluded; possibilities include vertebral artery dissection, epidural hematoma, infarction of the spinal cord, and stroke. Previous studies ${ }^{4}$ have postulated that the mechanism could involve alteration in cerebrospinal fluid volume, composition, and pressure as well as the systemic effect of corticosteroid, specifically interacting with steroid receptors located along the efferent limb of the reflex arc..$^{5}$ Additional proposed mechanisms include sympathetic blocks of the sympathetic chain located along the thoracic vertebrate leading to an overdrive of parasympathetic activity. Along a similar mechanism, stimulation of the phrenic nerve and the vagus nerve by the injectate has been proposed as well.

In the presented case, betamethasone was used, and there have been cases reported of persistent hiccups following betamethasone epidural injection with and without local anesthetic. ${ }^{6}$ Different steroids have been implicated in different case reports, and switching from one steroid to another has prevented recurrence. ${ }^{1}$ Interestingly, there have been case reports of cervical epidural injections of local anesthetic without steroid ${ }^{7}$ for the treatment of singultus. Treatment algorithms generally progress with nonpharmacologic, conservative management initially, with progression to pharmacologic therapy. This generally includes monotherapy with gabapentin, baclofen, and pregabalin and may progress to dual therapy or addition of medications including metoclopramide and thorazine. For the most persistent cases, phrenic nerve blocks are an option as well as peripheral nerve stimulation.

\section{Conclusion}

Persistent hiccups can be a distressing occurrence for patients. The potential causes are numerous, and it is critical that serious pathology is ruled out as the underlying cause. They are a rare occurrence following image-guided procedures, and the underlying pathophysiology is not entirely understood. It is helpful to follow a stepwise, algorithmic approach to diagnose and treat persistent hiccups.

\section{Disclosure}

The authors report no conflicts of interest in this work.

\section{References}

1. Abbasi A, Roque-Dang CM, Molhotra G. Persistent Hiccups After Interventional Pain Procedures: a Case Series and Review. PMR. 2012; 4:144-151.

2. Steger M, Schneemann M, Fox M. Systemic review: the pathogenesis and pharmacological treatment of hiccups. Alimentary Pharmacology and Therapeutics. 2015;42(9):1037-1050.

3. Kohse EK, Hollman MW, Bardenheurer HJ, Kessler J. Chronic Hiccups: An Underestimated Problem. Anesthetic Clinical Pharmacology. 2017;125(4):1169-1183.

4. Odonkor CA, Smith B, Rivera K, Chhatre A. Persistent Singultus Associated with Lumbar Epidural Steroid Injection in a Septuagenarian, A Case Report and Review. American Journal of Physical Medicine and Rehabilitation. 2017;96:e1-e4.

5. Dickerman R, Overby C, Eisenberg M, Hollis P, Levine M. The steroidresponsive hiccup reflex arc: Competitive binding to the corticosteroidreceptor? Neuroendocrinology Letters 24(3/4):167-169.

6. Slipman CW, Shin CH, Patel RK, et al. Persistent hiccup associated with thoracic epidural injection. Am J Phys Med Rehabil. 2001;80:618-21.

7. Sato S, Asakura N, Endo T, Naito H. Cervical Epidural Block Can Relieve Postoperative Intractable Hiccups. Anesthesiology. 1993; 78(6):1184-1186.
International Medical Case Reports Journal

Publish your work in this journal

The International Medical Case Reports Journal is an international, peer-reviewed open-access journal publishing original case reports from all medical specialties. Previously unpublished medical posters are also accepted relating to any area of clinical or preclinical science. Submissions should not normally exceed 2,000 words or

\section{Dovepress}

4 published pages including figures, diagrams and references. The manuscript management system is completely online and includes a very quick and fair peer-review system, which is all easy to use. Visit http://www.dovepress.com/testimonials.php to read real quotes from published authors. 